\title{
A role for the NPM1/PTPN14/YAP axis in mediating hypoxia-induced chemoresistance to sorafenib in hepatocellular carcinoma
}

\author{
Dengke Zhang ${ }^{\dagger}$, Fazong $\mathrm{Wu}^{\dagger}$, Jingjing Song ${ }^{\dagger}$, Miaomiao Meng, Xiaoxi Fan, Chenying Lu, Qiaoyou Weng, \\ Shiji Fang, Liyun Zheng, Bufu Tang, Yang Yang, Jianfei Tu, Min Xu, Zhongwei Zhao* and Jiansong Ji ${ }^{*}$ (D)
}

\begin{abstract}
Background: Tumor microenvironments are characterized by resistance to chemotherapeutic agents and radiotherapy. Hypoxia plays an important role in the development of tumor resistance, as well as the generation of metastatic potential. YAP also participates in the regulation of hypoxia-mediated chemoresistance, and is negatively regulated by protein tyrosine phosphatase non-receptor type 14 (PTPN14).
\end{abstract}

Methods: The PTPN14 expression in hepatocellular carcinoma (HCC) tissues were evaluated by qRT-PCR, western blot and tissue microarrays. The effect of PTPN14 on HCC progression was investigated in vitro and in vivo.

Results: Here, we report that PTPN14 expression was downregulated in HCC tissues and cell lines. Silencing PTPN14 significantly enhanced proliferation, migration, invasion of HepG2 cells in vitro and tumor growth and metastasis in vivo, whereas overexpression of PTPN14 significantly inhibited these abilities in SK-Hep1 cells. We also found that hypoxia-induced nuclear translocation and accumulation of PTPN14 led to resistance to sorafenib in HCC cells. Further mechanistic studies suggested that NPM1 regulates PTPN14 localization, and that NPM1 regulates YAP by retaining PTPN14 in the nucleus under hypoxic conditions.

Conclusions: These data suggest that a therapeutic strategy against chemoresistant HCC may involve disruption of NPM1-mediated regulation of YAP by retaining PTPN14 in the nucleus under hypoxic conditions.

Keywords: PTPN14, Hepatocellular carcinoma, Hypoxia, NPM1, YAP, Nuclear translocation

\section{Background}

Hepatocellular carcinoma (HCC) is the fifth most common cancer worldwide, and is the second most common cause of cancer death in the world $[1,2]$. Despite substantial progress in cancer therapeutics, prognosis in patients with HCC remains low [3, 4]. Common predisposing

\footnotetext{
*Correspondence: zhaozhongwei@zju.edu.cn; Ischrjjs@163.com ${ }^{\dagger}$ Dengke Zhang, Fazong Wu and Jingjing Song have contributed equally to this work and share first authorship

Zhejiang Provincial Key Laboratory of Imaging Diagnosis and Minimally Invasive Intervention Research, Lishui Hospital of Zhejiang University, The Fifth Affiliated Hospital of Wenzhou Medical University, Lishui 323000, China
}

conditions for HCC include end-stage liver fibrosis and cirrhosis, as well as chronic inflammation secondary to viral infections, chemical exposure, autoimmune diseases and metabolic conditions $[5,6]$.

Solid tumors such as HCC are characterized by areas of hypoxia, for various reasons including the absence of access to a blood supply $[7,8]$. Tumor hypoxia is associated with radioresistance, chemoresistance and metastasis, eventually leading to cancer progression and poor prognosis $[9,10]$. Nuclear translocation and activation of yes-associated protein (YAP) by hypoxia contributes to chemoresistance in hepatocellular carcinoma cells [11, 12]. YAP binds to hypoxia-inducible factor- $1 \alpha$ (HIF-1 $\alpha)$ original author(s) and the source, provide a link to the Creative Commons licence, and indicate if changes were made. The images or other third party material in this article are included in the article's Creative Commons licence, unless indicated otherwise in a credit line to the material. If material is not included in the article's Creative Commons licence and your intended use is not permitted by statutory regulation or exceeds the permitted use, you will need to obtain permission directly from the copyright holder. To view a copy of this licence, visit http://creativecommons.org/licenses/by/4.0/. The Creative Commons Public Domain Dedication waiver (http://creativeco mmons.org/publicdomain/zero/1.0/) applies to the data made available in this article, unless otherwise stated in a credit line to the data. 
and sustains HIF- $1 \alpha$ protein stability to promote $\mathrm{HCC}$ cell glycolysis under hypoxic stress $[11,13]$.

Protein tyrosine phosphatase non-receptor type 14 (PTPN14) interacts with and negatively regulates the oncogenic function of YAP $[14,15]$. PTPN14 suppresses pancreatic cell proliferation and transformation [16, 17]. PTPN14 knockdown enhances osteosarcoma cells colony formation $[8,18]$. Nevertheless, the role of PTPN14 and its relationship with YAP in HCC remains largely unknown.

PTPN14 can be localized in both the cytoplasm and nucleus [19]. In the current study, we show that PTPN14 localizes to the nucleus under hypoxic conditions, even though no classical nuclear localization sequence (NLS) has been reported or predicted in PTPN14. It has been speculated that the nuclear localization of PTPN14 may be achieved by its interaction with partner protein(s) with an NLS sequence. Nucleophosmin (NPM1/B23) interacts with several protein partners and is localized primarily in nucleoli. However, NPM1 shuttles between the nucleus and the cytoplasm, and sustained cytoplasmic distribution contributes to its tumor-promoting activities [20, 21]. NPM1 is a nucleolar phosphoprotein that is involved in many cellular processes and has both oncogenic and growth suppressing activities. NPM1 interacts with activating transcription factor 5 (ATF5) protein and promotes proteasome- and caspase-dependent ATF5 degradation in HCC cells [22, 23]. NPM1 interacts with several protein partners, modulating their stability. Importantly, NPM1 appears to play a fundamental role in nuclear localization of these proteins. According to the BioGRID database, PTPN14 is predicted to interact with NPM1. Since the mechanisms of hypoxia-induced chemoresistance in HCC have not been fully elucidated, we conducted the following study to examine the roles of PTPN14, YAP and NPM1 in generation of resistance to the chemotherapeutic agent sorafenib.

\section{Methods}

\section{Tissue samples}

Quantitative PCR and western blotting were performed on fresh HCC samples that had been collected from patients who underwent surgical resection at Lishui Hospital of Zhejiang University (Zhejiang, China). The Ethics Committee of Lishui Hospital of Zhejiang University approved this study. The protocols were in accordance with the Declaration of Helsinki. Informed consent was obtained from all patients.

\section{Tissue microarray}

HCC tissue microarrays (TMA) were purchased from Servicebio Technology Co. (Wuhan, China), and a standard protocol was used for immunostaining of the TMAs.
Immunohistochemistry was performed to determine the PTPN14 (1:150, Santa Cruz Biotechnology, Santa Cruz, CA, USA) levels. Briefly, paraffin was removed from sections, after which they were rehydrated and placed in a microwave oven for heat-induced epitope retrieval. Endogenous peroxide activity was quenched with $3 \%$ $\mathrm{H}_{2} \mathrm{O}_{2}$. Sections were then blocked in $5 \%$ fetal bovine serum (FBS) and incubated overnight at $4{ }^{\circ} \mathrm{C}$ with primary antibodies. The following day, horseradish peroxidase secondary antibodies (Invitrogen) were applied and sections were exposed to 3 3'-diaminobenzidine (Zhongshan Golden Bridge Biotechnology, Beijing, China) and counterstained with hematoxylin.

The histochemistry score (H-score) was calculated as previously described [24]. H-Scores were calculated as follows: $\mathrm{H}$-score $=$ (percentage of cells of weak intensity $\times 1)+($ percentage of cells of moderate intensity $\times 2)+($ percentage of cells of strong intensity $\times 3$ ). Samples with an $\mathrm{H}$-score of more than the median were considered to be high; those less than the median were considered low.

\section{Cell culture}

We obtained human HCC cells (Huh7, HepG2 and SKHEP1) and LO2 cells from the Shanghai Institute of Cell Biology, Chinese Academy of Sciences (Shanghai, China). We cultured HepG2 and LO2 cells in RPMI 1640 medium (Gibco BRL, Rockville, MD, USA) with $10 \%$ FBS (Gibco). Huh7 cells were cultured in DMEM medium (Gibco) with 10\% FBS. SK-HEP1 cells were grown in MEM medium (Gibco) with 10\% FBS. All cell lines were maintained in medium supplemented with $1 \%$ penicillin/ streptomycin (Gibco) at $37{ }^{\circ} \mathrm{C}$, in a humidified atmosphere of $5 \% \mathrm{CO}_{2}$. Hypoxia was induced by incubating cells at $37{ }^{\circ} \mathrm{C}$ in an atmosphere containing $93 \% \mathrm{~N}_{2}, 5 \%$ $\mathrm{CO}_{2}$ and $2 \% \mathrm{O}_{2}$ for $24 \mathrm{~h}$. Atmospheric conditions were maintained using a triple-gas incubator(Huaxi Electronic Tec., China). Triple-gas incubator by controlling the input of $\mathrm{O}_{2}$ or $\mathrm{N}_{2}$, with zirconia $\left(\mathrm{ZrO}_{2}\right)$ sensor to achieve control over $\mathrm{O}_{2}$ content, to perform three gas control of $\mathrm{O}_{2}, \mathrm{~N}_{2}$ and $\mathrm{CO}_{2}$. When $\mathrm{O}_{2}$ gas concentration was less than $19 \%$, the advanced $\mathrm{N}_{2}$ gas was used, after reaching the $\mathrm{O} 2$ concentration set value, and then the way $\mathrm{CO}_{2}$ gas was re fed, to ensure the accuracy of $\mathrm{CO}_{2}$ gas concentration and $\mathrm{O}_{2}$ concentration. When $\mathrm{O}_{2}$ gas concentration was more than $23 \%$, the method of using advanced $\mathrm{O}_{2}$ gas, after reaching the $\mathrm{O}_{2}$ concentration set value, and then the way $\mathrm{CO}_{2}$ gas was re fed, to ensure the accuracy of $\mathrm{CO}_{2}$ gas concentration and $\mathrm{O}_{2}$ concentration.

\section{Cell transfection and stable cell line generation}

For PTPN14 knockdown, shRNAs for human PTPN14 were designed and constructed in a GV112 lentiviral 
expression plasmid (Shanghai Genechem Co., Ltd., Shanghai, China). shRNA plasmids were constructed using PTPN14 target (5'-GGTCTACAGCAACAAACT TGT- $\left.3^{\prime \prime}\right)$ and a scrambled sequence $\left(5^{\prime}\right.$-TTTAGACTT TATGAGCTAA- $3^{\prime}$ ) was used as the negative control.

For PTPN14 overexpression, using cDNA from the human PTPN14 gene, we amplified a fragment encoding the full-length PTPN14 open reading frame sequence using PCR and then cloned it into GV341 lentiviral expression plasmids (Shanghai Genechem Co., Ltd.). Lentivirus with an empty vector served as the negative control.

For production of recombinant lentiviruses, we co-transfected HEK293T cells with their respective recombinant expression lentivectors together with enveloped, packaged plasmids using the Lipofectamine $^{\text {TM }} 2000$ transfection reagent (Life Technologies, Gaithersberg, MD, USA). The viral supernatants were harvested $48 \mathrm{~h}$ after transfection, and viral titers were measured. The recombinant lentivirus was infected into HCC cells for $48 \mathrm{~h}$ in medium containing $6 \mu \mathrm{g} / \mathrm{ml}$ polybrene (Sigma-Aldrich Co., St. Louis, MO, USA). Fresh culture medium containing $2 \mu \mathrm{g} / \mathrm{ml}$ puromycin was added to select stable transfected cell lines.

siRNAs targeting NPM1 (siNPM1) and YAP (siYAP) were synthesized by Genepharm Technologies (Shanghai, China). Full-length NPM1 was amplified by PCR and subcloned into the pcDNA3-based expression vector (Invitrogen, Carlsbad, CA, USA). Plasmids and all siRNA transfections were performed using Lipofectamine 2000. For transient transfection, we transfected cells with plasmids or siRNAs at various concentrations as indicated for $48 \mathrm{~h}$ before performing functional assays.

\section{Total RNA extraction and quantitative real-time} polymerase chain reaction (qRT-PCR)

Total RNA was extracted using TRIzol (Life Technologies). We performed reverse transcription into cDNA using the SuperScript III cDNA synthesis kit (Life Technologies). We employed cDNA samples $(2 \mu \mathrm{l})$ for qRT-PCR using SYBR Green PCR Master Mix (Takara, Dalian, China) for 40 cycles on an ABI Prism 7500 detection system (Life Technologies). The following primers were used for qRT-PCR: PTPN14, forward, 5'-TCCCTGTAAAGGACAATCAT-3' and reverse, 5'-GTGGCAAACAACCGAGAA-3'; GAPDH, forward, $5^{\prime}$-TCAAGAAGGTGGTGAAGCAGG-3' and reverse, 5'-TCAAAGGTGGAGGAGTGGGT-3'. We used the $2^{-\Delta \Delta C t}$ method for relative quantification of gene expression and normalized the data to $\beta$-actin expression.

\section{Western blotting}

Proteins was extracted using RIPA lysis buffer (Beyotime Institute of Biotechnology, Jiangsu, China) according to the manufacturer's instructions. For nuclear proteins, we used NE-PER ${ }^{\mathrm{TM}}$ Nuclear and Cytoplasmic Extraction Reagents (Thermo Fisher Scientific, Rockford, IL, USA) according to the manufacturer's instructions. We determined protein concentrations using the bicinchoninic acid method (BCA, Pierce, Rockford, IL, USA). Then, $30 \mu \mathrm{g}$ of total protein was separated using $10 \%$ sodium dodecyl sulfate polyacrylamide gel electrophoresis (SDS-PAGE), followed by electrotransfer onto PVDF membranes (Millipore, Bedford, MA, USA). Following blocking, we incubated membranes with antibodies specific for PTPN14 (Santa Cruz Biotechnology, Santa Cruz, CA, USA), YAP or phosphorylated-YAP (p-YAP) (Ser127) (Cell Signaling Technology, Danvers, MA, USA), GAPDH or lamin B (Abcam, Cambridge, MA, USA). Finally, we incubated blots with goat anti-rabbit or antimouse secondary antibodies (Santa Cruz Biotechnology) and visualized signals with enhanced chemiluminescence (Pierce).

\section{Cell viability assay}

We seeded cells in $100 \mu \mathrm{l}$ growth medium at $8 \times 10^{3}$ cells per well in 96-well plates. Following overnight incubation, we treated cells with or without sorafenib (SigmaAldrich), then incubated the cells with $10 \mu \mathrm{l}$ of MTT (5 mg/ml, Cat.11465007001, Sigma-Aldrich) for $4 \mathrm{~h}$ at $37{ }^{\circ} \mathrm{C}$. We measured cell viability using a microplate reader (BioTek, Winooski, VT, USA) at $570 \mathrm{~nm}$. $\mathrm{IC}_{50}$ was calculated using GraphPad Prism 5. Each experiment was performed at least three times using separate cultures.

\section{Colony formation assay}

We seeded cells into 6-well plates at about 500 cells/well and cultured them in RPMI-1640 containing 10\% fetal bovine serum. At day 14 , the plates were fixed in $4 \%$ paraformaldehyde and stained with $1 \%$ crystal violet sequentially. We counted colonies with $\geq 50$ cells manually under a dissection microscope.

\section{Invasion and migration assays}

After treatment, cells were placed in Transwell chambers ( $8 \mu \mathrm{m}$ pore; BD Biosciences, San Jose, CA, USA) as previously described. For the invasion assay, $1 \times 10^{5}$ cells were seeded into the upper chamber coated with Matrigel in a cell invasion system (BD Biosciences). The lower chamber was filled with medium. After incubation, invading cells were fixed with methanol, visualized by staining with $0.1 \%$ crystal violet and counted. For the migration assay, $5 \times 10^{4}$ cells were seeded into the upper chamber 
and the lower chamber was filled with medium. After incubation, the cells that had migrated through the membrane were fixed, stained and counted.

\section{Immunofluorescent staining and confocal microscopy}

Confocal microscopic imaging of immunofluorescent staining. Briefly, cells were washed and applied to slides by cytospinning. Then, the cells were fixed for $20 \mathrm{~min}$ in PBS containing $4 \%$ paraformaldehyde, permeabilized in $1 \%$ Triton X-100 for $20 \mathrm{~min}$, then incubated in blocking buffer (5\% FBS in PBS) for $30 \mathrm{~min}$. The cells were rinsed in PBS and incubated overnight at $4{ }^{\circ} \mathrm{C}$ in dilution buffer containing primary antibodies against PTPN14 (1:100, Santa Cruz Biotechnology, Santa Cruz, CA, USA) or YAP (1:200, Cell Signaling Technology, Danvers, MA, USA). The cells were washed three times with PBS before being incubated with an appropriate fluorochrome-conjugated secondary antibody (Alexa Fluor 488- or Alexa Fluor 594-conjugated secondary antibody, Invitrogen) for $1 \mathrm{~h}$ at $37^{\circ} \mathrm{C}$ in the dark. After nuclear counterstaining with 4, 6-diamidino-2-phenylindole (DAPI, Beyotime, China), coverslips were fixed with mounting medium and cells were visualized using a light microscope (Nikon, Tokyo, Japan).

\section{Co-immunoprecipitation}

For co-immunoprecipitation (Co-IP), cells subjected to hypoxia for various durations were harvested. Total lysates were incubated with the human PTPN14 antibody (Santa Cruz Biotechnology) overnight. After overnight incubation, we added protein-G or protein-A sepharose CL-4B (Invitrogen) and incubated the mixture for another $4 \mathrm{~h}$. We then subjected the suspension to several pull-down assays, washed the mixture five times in PBS, and PTPN14-associated protein complexes were separated using SDS-PAGE. Finally, we immunoblotted the membranes using antibodies against human NPM1 or PTPN14.

\section{In vivo tumorigenicity and pulmonary metastasis}

Animal studies were approved by the Lishui Hospital of Zhejiang University, Zhejiang, China. Male athymic $\mathrm{BALB} / \mathrm{c}$ nude mice (4-5 weeks old) were used for this study (Shanghai Slac Laboratory Animal Co., China). For in vivo tumorigenicity experiments, we subcutaneously injected equal numbers $\left(1 \times 10^{7}\right)$ of transduced HCC cells into each mouse flank. We measured tumor volumes using the formula: volume $\left(\mathrm{mm}^{3}\right)=(\text { width })^{2} \times$ length $/ 2$, and mice were euthanized using $\mathrm{CO}_{2}$ inhalation $\left(\mathrm{CO}_{2}\right.$ flow rate, $20 \%$ of chamber volume per minute) 5 weeks after injection.

To generate in vivo models of pulmonary metastasis, we injected luciferase transduced HCC cells into nude mice through the tail vein. After about 8 weeks, mice were injected with D-luciferin $(150 \mathrm{mg} / \mathrm{kg})$, anesthetized with $5 \%$ isofluorane, and tumor metastases were visualized and imaged using a whole-body fluorescent imaging system. At the end of the experiments, mice were euthanized using $\mathrm{CO}_{2}$ inhalation $\left(\mathrm{CO}_{2}\right.$ flow rate, $20 \%$ of chamber volume per minute), and the whole lungs were excised.

\section{Statistical analysis}

Data were expressed as mean $\pm \mathrm{SD}$. The differences in mean values between two groups were analyzed using the Student's $t$ test, and differences in mean values between several groups were analyzed using one-way ANOVA. All statistical analyses were performed using GraphPad Prism 5.0 software. $p<0.05$ was considered statistically significant.

\section{Results}

\section{Downregulation of PTPN14 in HCC tissues}

We measured PTPN14 mRNA levels in 20 paired HCC and corresponding peritumoral liver tissues using qRTPCR. We found significantly lower levels of PTPN14 expression in HCC tissues than in peritumor tissue ( $\mathrm{p}$ $<0.01$ ) (Fig. 1A). Consistent with this result, western blots demonstrated that PTPN14 protein was present in higher levels in peritumor tissues than in HCC (Fig. 1B). This result was confirmed by immunohistochemical staining for PTPN14 in sections of tissue taken from patients with HCC (Fig. 1C, D).

\section{PTPN14 suppresses HCC growth and tumorigenesis in vitro and in vivo}

We next examined PTPN14 expression in various HCC cell lines (HepG2, Huh7 and SK-Hep1) using qRT-PCR (Fig. 2A) and western blotting (Fig. 2B), and compared expression in these cells to that of a normal hepatic cell line (LO2). We found that PTPN14 expression was significantly lower in HCC lines than in the normal hepatic cell line. To test the effect of PTPN14 on cell proliferation in vitro, we stably knocked down PTPN14 expression in HepG2 cells and overexpressed PTPN14 in SK-Hep1 cells (Fig. 2C). We found that PTPN14 knockdown significantly enhanced proliferation, while overexpression significantly inhibited proliferation over a $96-\mathrm{h}$ time course (Fig. 2D, E).

To confirm these results in vivo, we subcutaneously injected HepG2 cells with stable knockdown of PTPN14 as well as SK-Hep1 cells with stable overexpression of PTPN14 into nude mice and measured tumor growth over 5 weeks (Fig. 2F). The tumor volume was significantly higher in HepG2 cells with PTPN14 knockdown and was significantly lower in SK-Hep1 cells with 


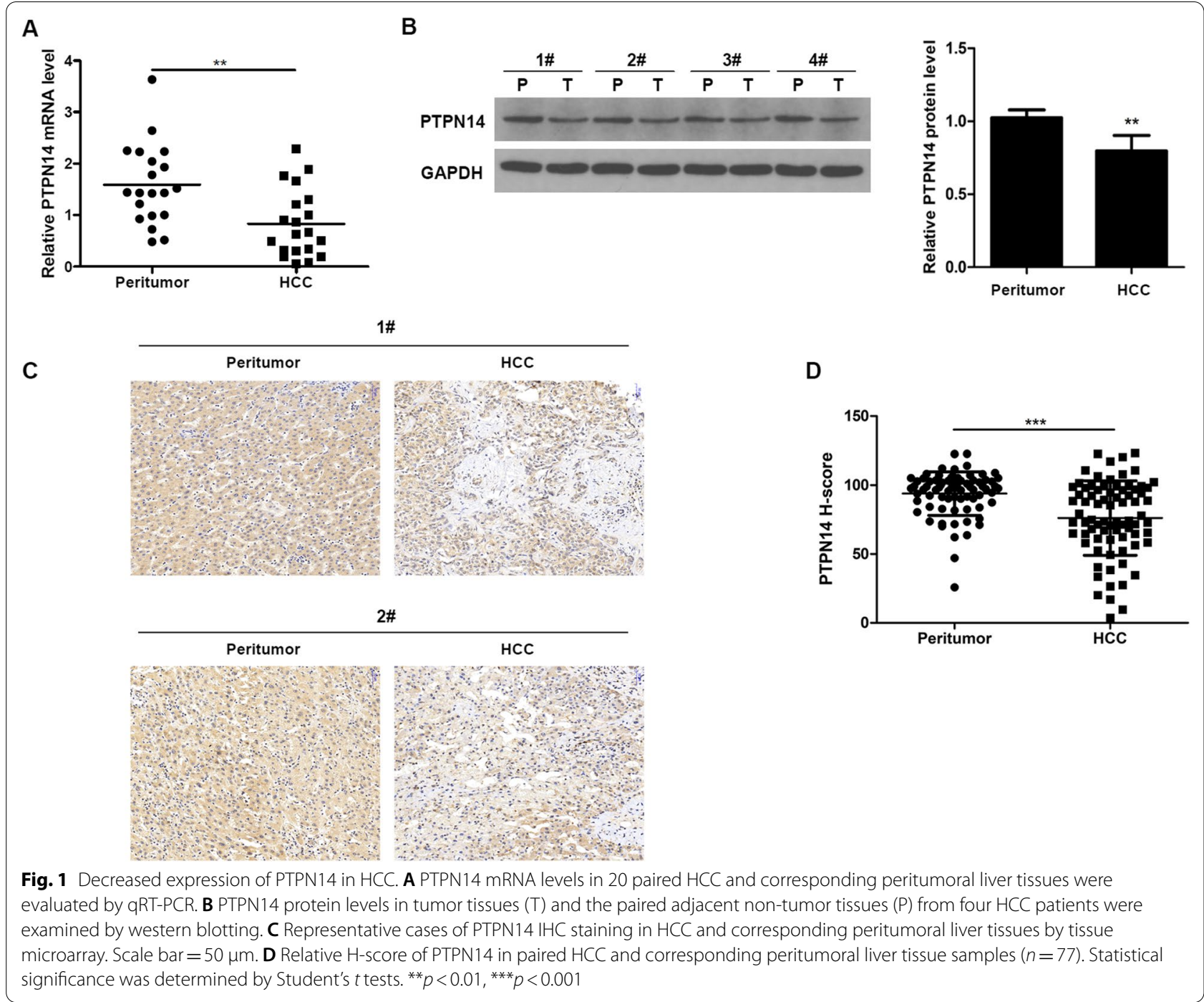

PTPN14 overexpression (Fig. 2G). Similarly, tumor weight was significantly higher in HepG2 cells with PTPN14 knockdown and significantly lower in SKHep1 cells with PTPN14 overexpression (Fig. 2H). These results suggest that, in vivo, PTPN14 suppresses tumor growth and that, conversely, absence of PTPN14 promotes tumor growth in HCC.

\section{PTPN14 suppresses HCC invasion and migration in vitro} and in vivo

We next examined the effects of PTPN14 on HCC cell invasion and migration in vitro (Fig. 3A, B). Transwell assays revealed that when PTPN14 was stably knocked down, migration and invasion were significantly greater than in the controls (Fig. 3A). Conversely, when PTPN14 was stably overexpressed, migration and invasion were significantly less than in the controls (Fig. 3B). We then measured the effect of PTPN14 knockdown or overexpression on the extent of pulmonary metastasis. We injected transduced HCC cells into nude mice via the tail vein. After about 8 weeks, the mice were anesthetized. We imaged the mice using whole-body fluorescent imaging (Fig. 3C). We found that PTPN14 knockdown significantly enhanced pulmonary metastases, whereas overexpression significantly inhibited metastases. These results suggest that PTPN14 expression inhibits tumor cell migration and invasion in HCC cells, and that conversely, PTPN14 blockade promotes tumor invasion and migration.

\section{Nuclear translocation of PTPN14 is induced under hypoxic conditions and is essential for hypoxia-induced drug resistance}

To study the effects of PTPN14 in mediating the effects of hypoxia-induced drug resistance, we first examined the effects of the tyrosine kinase inhibitor sorafenib 

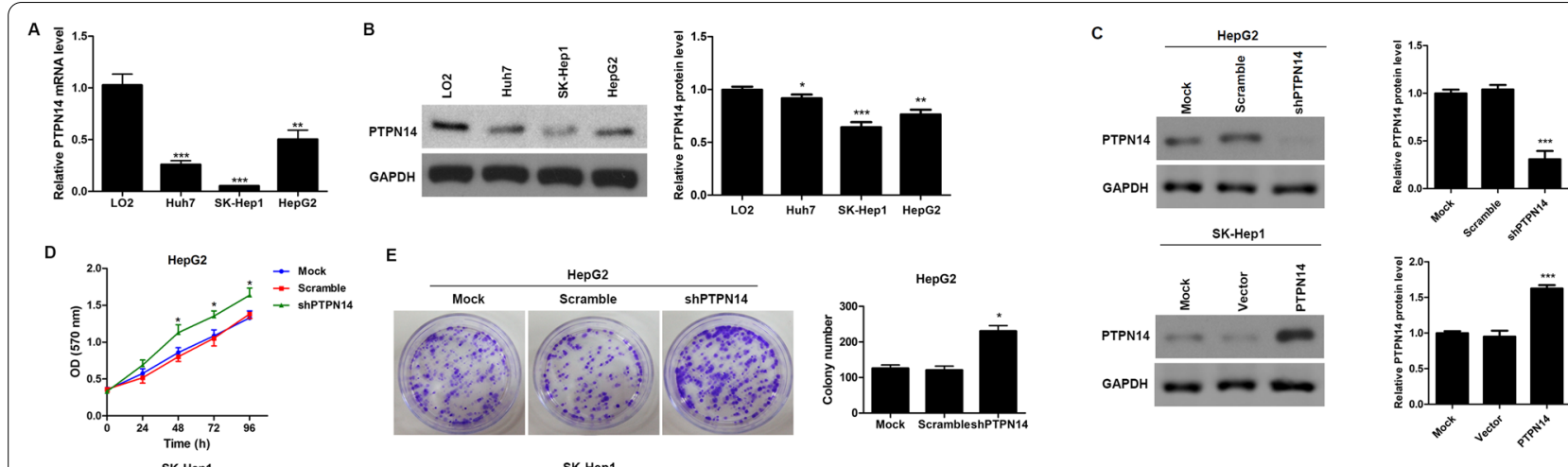

E
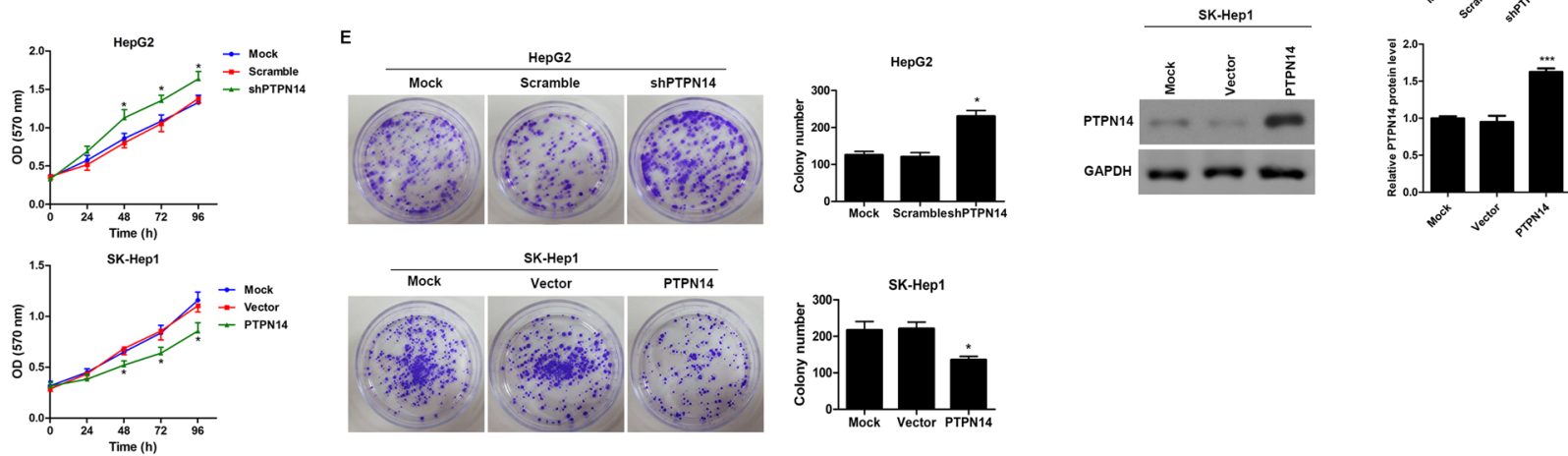

$\mathrm{F}$
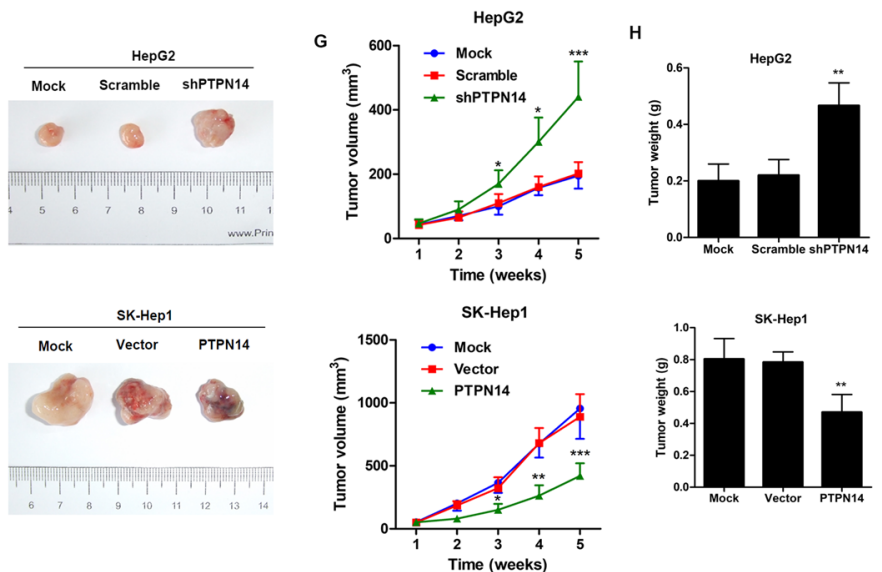

Fig. 2 PTPN14 inhibits HCC growth and tumorigenesis in vitro and in vivo. The expression of PTPN14 in different HCC cell lines with varied metastatic potential was analyzed by qRT-PCR (A) and western blotting (B). C Verification of the efficiency of PTPN14 knockdown in HepG2 cells or overexpression in SK-Hep1 cells. D Cell proliferation was determined by MTT assays in HepG2 cells with stable PTPN14 knockdown and SK-Hep1 cells with PTPN14 stable overexpression at the indicated times. E Representative images and quantification of cell clones in HepG2 cells with stable PTPN14 knockdown and SK-Hep1 cells with PTPN14 stable overexpression as determined by a colony formation assay. HepG2 cells with stable PTPN14 knockdown and SK-Hep1 cells with PTPN14 stable overexpression were injected subcutaneously into nude mice $\left(1 \times 10^{7}\right.$ cells per mouse, five mice per group). Mice and tumors were evaluated 5 weeks post-injection and representative images are shown (F). Tumor growth curve during the 5-week study period $(\mathbf{G})$ and tumor weights $(\mathbf{H})$ are shown. Data are shown as the mean $\pm \mathrm{SEM}$. Statistically significant differences were determined by Student's $t$ tests. ${ }^{*} p<0.05 ;{ }^{* *} p<0.01$ compared with the respective controls

$(5 \mu \mathrm{M})$ on PTPN14 expression in HepG2 cells under both normoxic $\left(20 \% \mathrm{O}_{2}\right)$ and hypoxic $\left(2 \% \mathrm{O}_{2}\right)$ conditions for $24 \mathrm{~h}$. We found that PTPN14 expression was significantly elevated by sorafenib treatment under normoxic conditions at both the mRNA level (Fig. 4A) and the protein level (Fig. 4B); this elevation persisted, though at lower levels, under hypoxic conditions. These findings suggest that sorafenib causes elevation of PTPN14 expression, a circumstance that may lead to inhibition of cancer cell proliferation, migration and invasion. We confirmed these findings using confocal microscopy. We examined the subcellular localization of PTPN14 in response to sorafenib under normoxic and hypoxic conditions, and found that sorafenib induced cytoplasmic PTPN14 expression, and hypoxia induced nuclear translocation of PTPN14; however, sorafenib-induced PTPN14 cytoplasmic translocation was reduced under hypoxic conditions (Fig. 4C). Moreover, PTPN14 protein levels in the cytosol were significantly reduced under hypoxic conditions as determined by WB (Fig. 4D).

We then looked at the effects of sorafenib and hypoxia over $72 \mathrm{~h}$ in HCC cells where PTPN14 was either knocked down or overexpressed. In HepG2 cells, PTPN14 knockdown elevated the $\mathrm{IC}_{50}$ of sorafenib, both in normoxic 

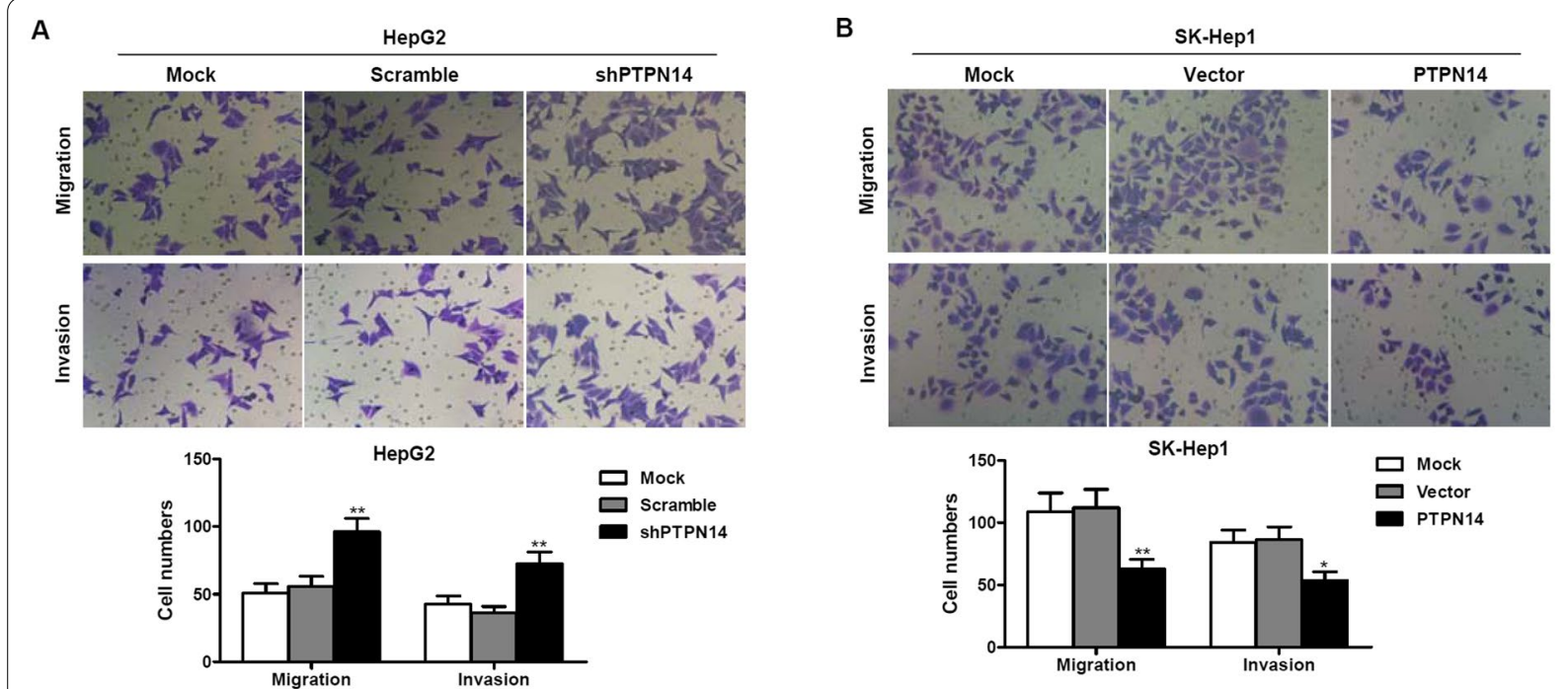

C
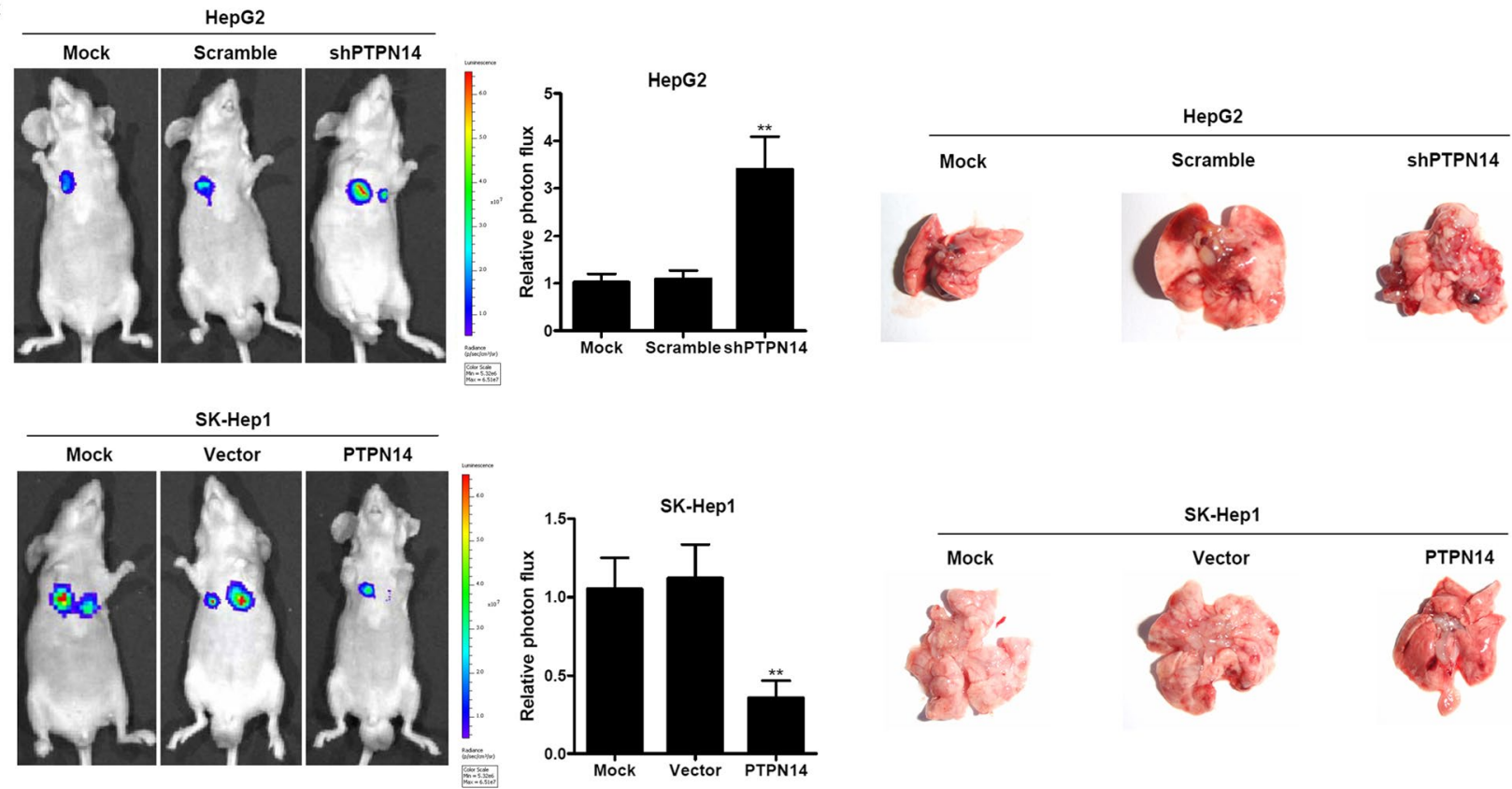

Fig. 3 PTPN14 suppresses HCC invasion and migration in vitro and in vivo. The migration and invasion of HepG2 cells with stable PTPN14 knockdown (A) and SK-Hep1 cells with PTPN14 stable overexpression (B) was assessed by a Transwell assay. The number of migrating and invading cells was counted in at least three different fields per sample. The data are shown as the means \pm SD $(n=3) .{ }^{*} p<0.05 ;{ }^{* *} p<0.01$ compared with the respective controls. C The pulmonary metastasis of HepG2 cells with stable PTPN14 knockdown and SK-Hep1 cells with PTPN14 stable overexpression was monitored by bioluminescence imaging in vivo. Pulmonary metastasis was observed using a whole-body fluorescent imaging system. Right, gross view of lung metastatic nodules. Relative photon flux of the two groups was calculated. The data are shown as the mean \pm SD $(n=5) .{ }^{* *} p<0.01$ compared with the respective controls

(See figure on next page.)

Fig. 4 Nuclear translocation of PTPN14 is induced under hypoxia and is required for hypoxia-induced drug resistance. PTPN14 mRNA levels (A) and protein levels (B) in HepG2 cells upon sorafenib $(5 \mu \mathrm{M})$ treatment under hypoxia $\left(2 \% \mathrm{O}_{2}\right)$ for $24 \mathrm{~h}$. C Representative immunofluorescence staining of PTPN14 in HepG2 cells upon sorafenib $(5 \mu \mathrm{M})$ treatment under normoxia $\left(20 \% \mathrm{O}_{2}\right)$ or hypoxia $\left(2 \% \mathrm{O}_{2}\right)$ for $24 \mathrm{~h}$. Scale bar $=20 \mu \mathrm{m}$. D PTPN14 protein levels within the cytoplasm and nucleus under normoxic and hypoxic conditions.E andF. HepG2 cells with stable PTPN14 knockdown (E) and SK-Hep1 cells with PTPN14 stable overexpression (F) were treated with the indicated doses of sorafenib under normoxia or hypoxia for $72 \mathrm{~h}$. Cell viability was calculated by MTT assays. The IC ${ }_{50}$ values derived from the dose-response curves are presented 


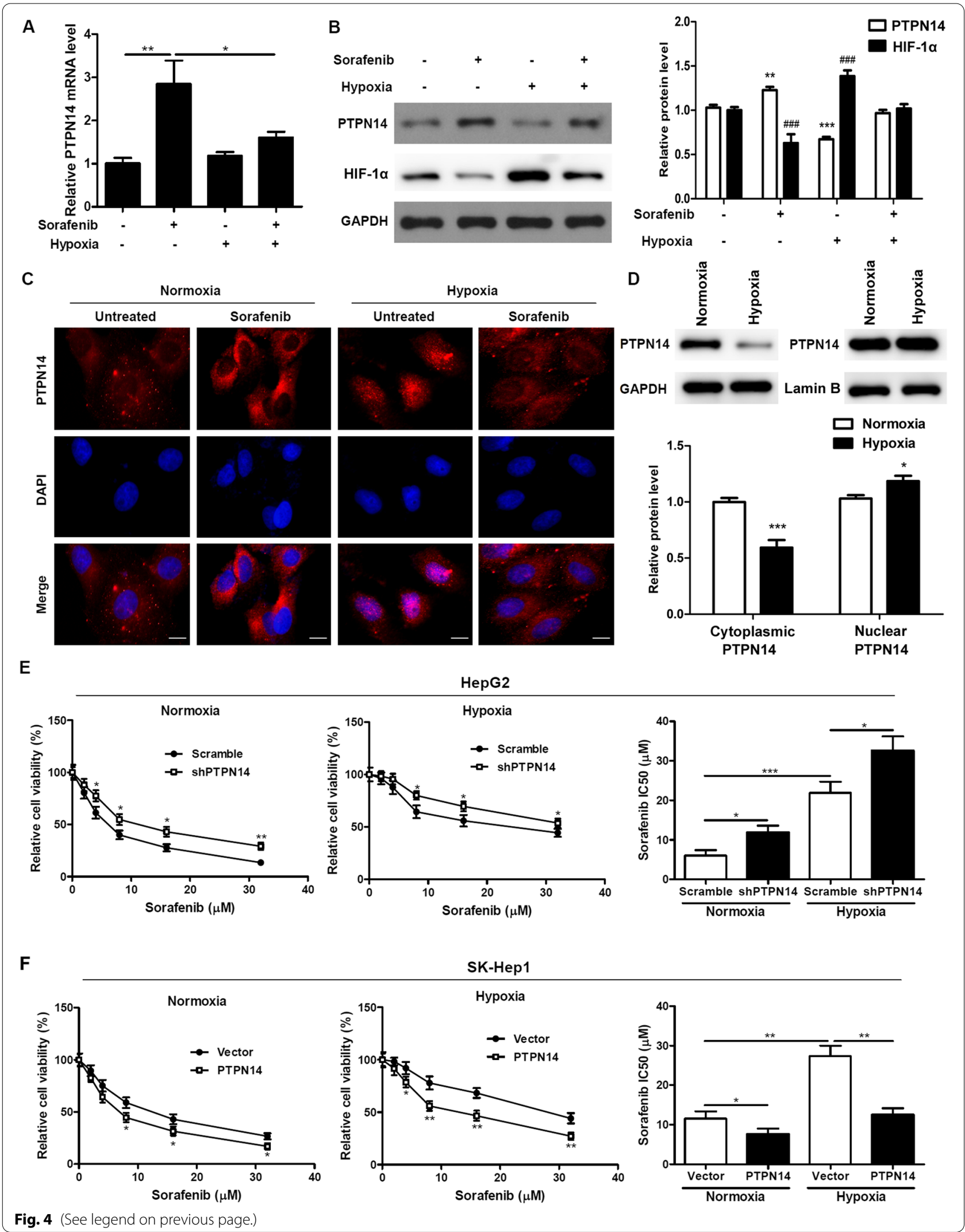


and hypoxic conditions (Fig. 4E), although hypoxia decreased the sensitivity of HepG2 cells to sorafenib, as demonstrated by an elevated $\mathrm{IC}_{50}$. Conversely, in SKHep1 cells, PTPN14 overexpression decreased the $\mathrm{IC}_{50}$ of sorafenib, both under normoxic and hypoxic conditions (Fig. 4F), despite the fact that the cells were less sensitive to sorafenib under hypoxic conditions. Taken together, these results suggest that hypoxia both increases PTPN14 nuclear translocation and decreases cell sensitivity to the chemotherapeutic agent sorafenib.

\section{NPM1 regulates PTPN14 localization under hypoxic conditions}

Using three web-based NLS prediction programs, PSORT, cNLS mapper and NLSdb, we found that PTPN14 does not contain any classical NLS sequences. Thus, we hypothesized that nuclear localization of PTPN14 is achieved by its interaction with other known nuclear proteins. Because the predicted interaction between PTPN14 and the protein nucleophosmin (NPM1/B23) are reported in BioGRID, we performed colocalization staining for PTPN14 and NPM1 in HepG2 cells, both under normoxic and hypoxic conditions for $24 \mathrm{~h}$. We found that PTPN14 and NPM1 colocalized in the nucleus under hypoxic conditions, and that hypoxia triggered the release of NPM1 from nucleoli (Fig. 5A). To verify this result, we performed a co-precipitation experiment. We added anti-PTPN14 antibodies to precipitated proteins harvested from HepG2 cells treated with or without hypoxia (Fig. 5B). We found that NPM1 co-precipitated with PTPN14 after treatment with hypoxia but not without hypoxia. This result suggests that hypoxic stress triggers nuclear localization of PTPN14.

We also performed localization assays of PTPN14 in HepG2 cells with NPM1 knockdown under normoxic and hypoxic conditions for $24 \mathrm{~h}$. We found that PTPN14 was mainly distributed in the cytoplasm under hypoxic conditions in NPM1-knockdown cells, whereas it remained in the nucleus of cells with normal expression of NPM1 (Fig. 5C). Taken together, these results suggest that NPM1 interacts with PTPN14 and that this interaction is required for nuclear retention of PTPN14 under hypoxic conditions.

Next, we examined the influence of PTPN14 or NPM1 knockdown on the effect of sorafenib on cell viability. The $\mathrm{IC}_{50}$ was measured using an MTT assay after $72 \mathrm{~h}$ of sorafenib treatment. We found that under normoxic conditions, knockdown of NPM1 increased sorafenib sensitivity of HepG2 cells, whereas this effect was abolished by PTPN14 knockdown (Fig. 5D). These findings indicate
A
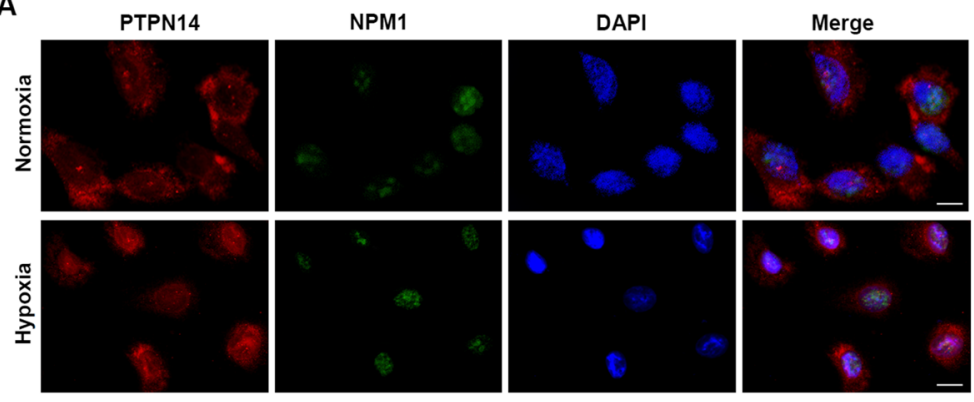

B

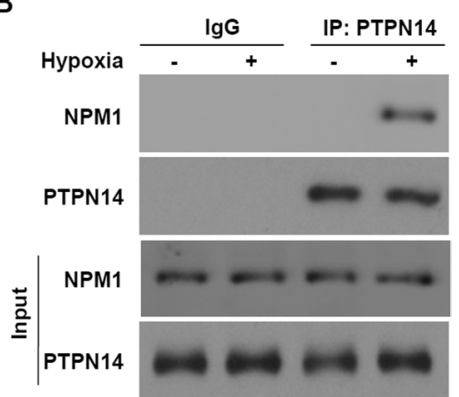

C

PTPN14

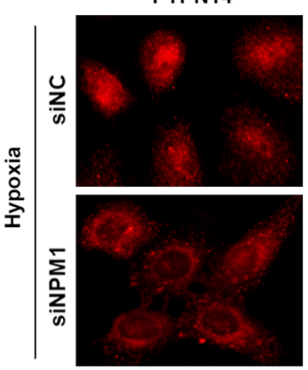

DAPI

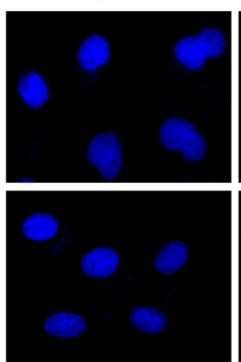

Merge

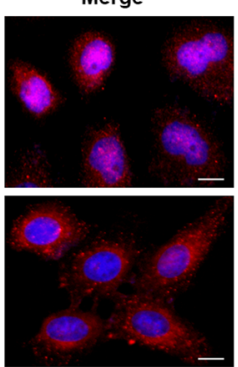

D

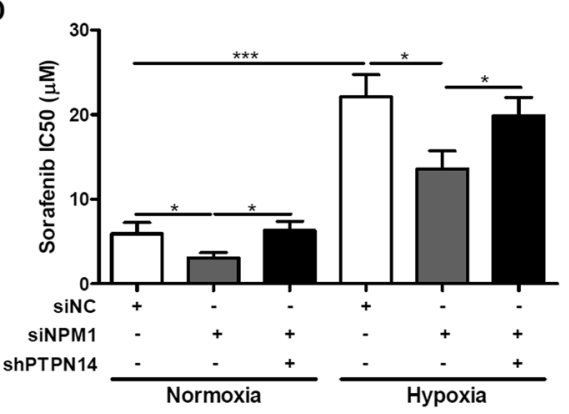

Fig. 5 NPM1 regulates PTPN14 localization under hypoxia. A Representative immunofluorescence staining of the localization of PTPN14 and NPM1 in HepG2 cells under normoxia $\left(20 \% \mathrm{O}_{2}\right)$ or hypoxia $\left(2 \% \mathrm{O}_{2}\right)$ for $24 \mathrm{~h}$. Scale bar $=20 \mu \mathrm{m}$. B Total lysate was harvested from HepG 2 cells after hypoxia for 0 or $24 \mathrm{~h}$. After the cells had been immunoprecipitated using PTPN14 antibody, their interaction with NPM1 was examined using the indicated antibodies. C Representative immunofluorescence staining of PTPN14 in HepG2 cells transfected with NPM1 siRNA (siNPM1) under hypoxic conditions $\left(2 \% \mathrm{O}_{2}\right)$ for $24 \mathrm{~h}$. Scale bar $=20 \mu \mathrm{m}$. D The $\mathrm{IC}_{50}$ was measured using an MTT assay after $72 \mathrm{~h}$ of sorafenib treatment 
that NPM1 regulates PTPN14 localization under hypoxic conditions and mediates sorafenib resistance through PTPN14.

\section{PTPN14 enhances sensitivity to sorafenib via repression of YAP under hypoxic conditions}

We next sought to determine whether PTPN14 activity inactivated YAP, and exerted an anti-tumor effect. To explore the role of YAP in the mechanism of action of PTPN14 with respect to sorafenib sensitivity, we performed localization experiments in HepG2 cells with and without stable PTPN14 knockdown, under both normoxic and hypoxic conditions. We found that YAP translocated to the nucleus under hypoxic conditions for $24 \mathrm{~h}$, and knockdown of PTPN14 enhanced hypoxia-induced nuclear translocation of YAP (Fig. 6A). In SK-Hep1 cells overexpressing PTPN14, hypoxia-induced nuclear translocation of YAP was attenuated by PTPN14 overexpression (Fig. 6B).

We then studied the effects of PTPN14 knockdown and overexpression on the levels of YAP and phosphorylated YAP (p-YAP) under normoxic and hypoxic conditions for

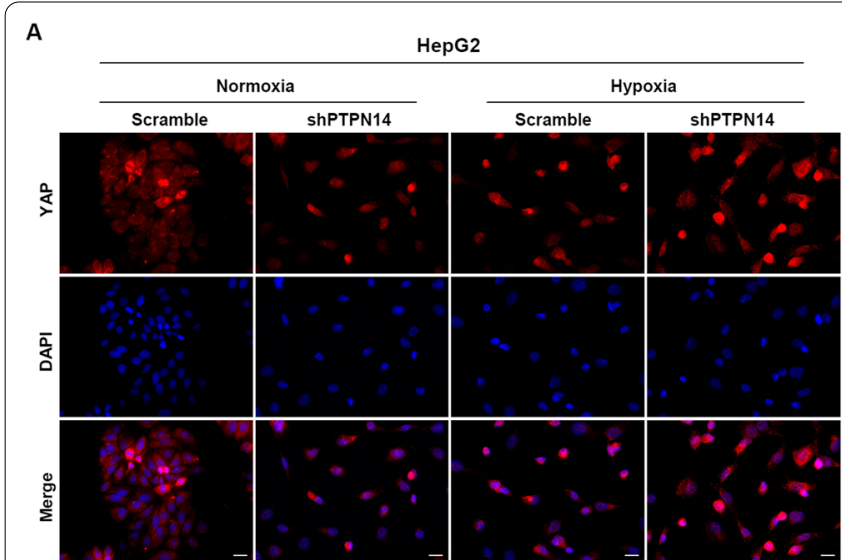

B

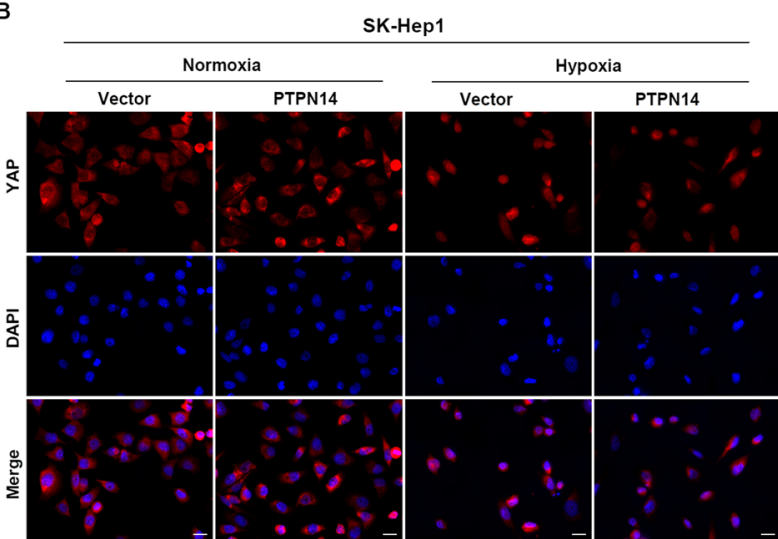

C
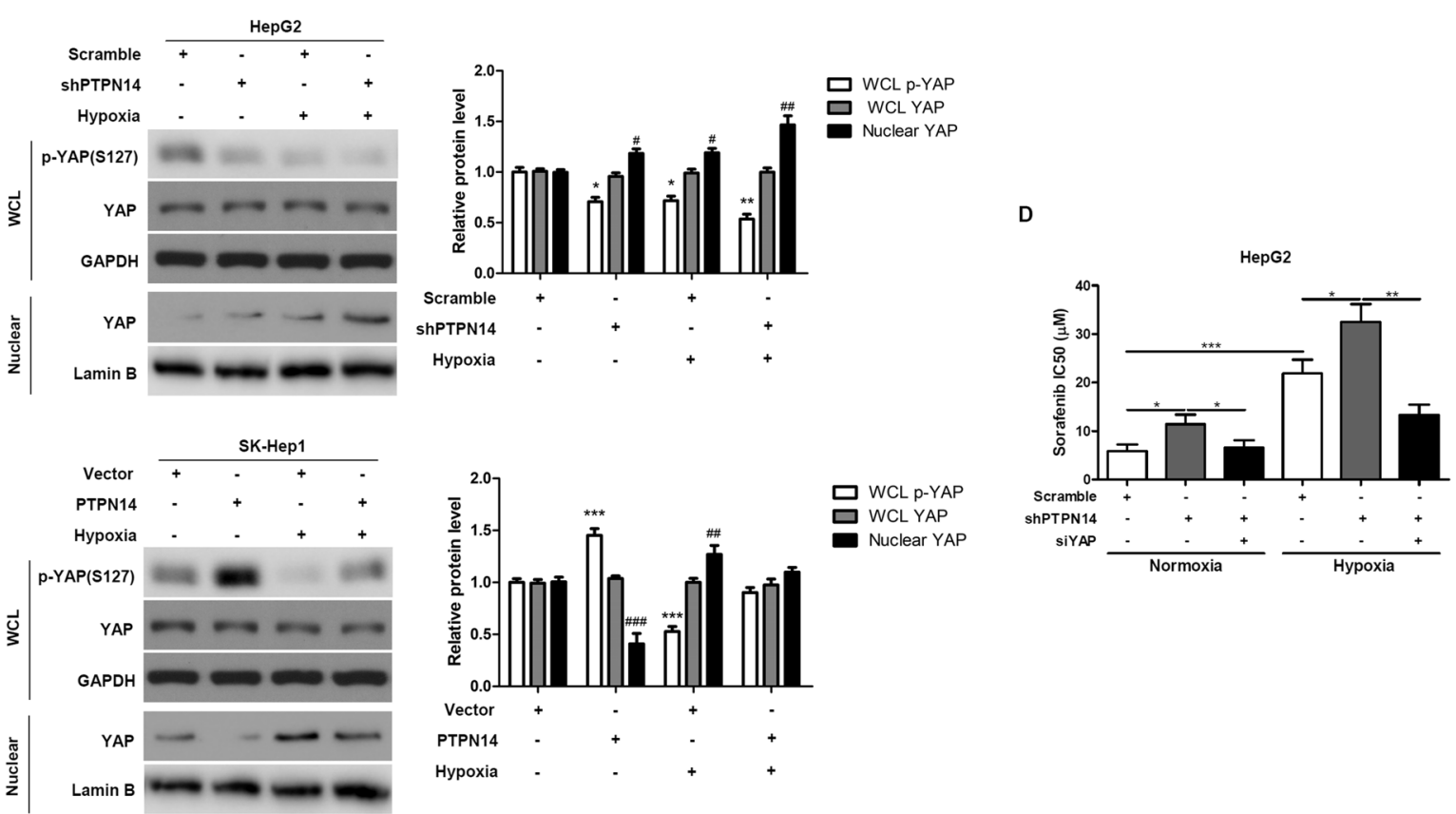

Fig. 6 PTPN14 regulates sensitivity to sorafenib through YAP under hypoxia. Representative immunofluorescence staining of the localization of YAP in HepG2 cells with stable PTPN14 knockdown (A) and SK-Hep1 cells with PTPN14 stable overexpression (B) under normoxia (20\% $\mathrm{O}_{2}$ ) or hypoxia $\left(2 \% \mathrm{O}_{2}\right)$ for $24 \mathrm{~h}$. Scale bar $=20 \mu \mathrm{m}$. C The expression of p-YAP and total YAP in the whole cell lysate (WCL) and nuclear fractions in HepG2 cells with stable PTPN14 knockdown and SK-Hep1 cells with PTPN14 stable overexpression under hypoxic conditions $\left(2 \% \mathrm{O}_{2}\right)$ for $24 \mathrm{~h}$ was examined by western blotting. D The $\mathrm{IC}_{50}$ was measured using an MTT assay after $72 \mathrm{~h}$ of sorafenib treatment. ${ }^{*} p<0.05 ;{ }^{* *} p<0.01 ;{ }^{* * *} p<0.001$ 
24 h. In HepG2 cells with stable knockdown of PTPN14, nuclear translocation of YAP induced by hypoxia was promoted by PTPN14 knockdown. The levels of p-YAP were diminished by PTPN14 knockdown under hypoxic conditions (Fig. 6C). Conversely, in SK-Hep1 cells that were stably overexpressing PTPN14, nuclear translocation of YAP was significantly diminished compared to control cells under both normoxic and hypoxic conditions (Fig. 6C).

We also measured the $\mathrm{IC}_{50}$ for sorafenib using an MTT assay after $72 \mathrm{~h}$ of treatment of the cells with either PTPN14 or YAP knockdown (Fig. 6D). We found that hypoxia significantly increased the $\mathrm{IC}_{50}$ of sorafenib, and that this effect was further augmented by PTPN14 knockdown. However, the effect of hypoxia and PTPN14 knockdown was abolished by knockdown of YAP expression. Taken together, these data suggest that under hypoxic conditions, PTPN14 enhances sensitivity to sorafenib via repression of YAP.

\section{NPM1 regulates YAP by retaining PTPN14 in the nucleus under hypoxic conditions}

To further explore the mechanism of action of PTPN14 under hypoxic conditions, we studied the effects of NPM1 under hypoxic conditions $\left(2 \% \mathrm{O}_{2}\right)$. We found that NPM1 knockdown prevented translocation of YAP to the nucleus, an effect that was partially reversed by PTPN14 knockdown (Fig. 7A, C). Conversely, NPM1 overexpression enhanced nuclear translocation of YAP in a manner that was partially reversed by PTPN14 overexpression (Fig. 7B, C). Furthermore, under hypoxic conditions, levels of p-YAP were significantly increased by NPM1 knockdown, in a manner that was partially reversed by PTPN14 knockdown (Fig. 7C). Levels of p-YAP were significantly enhanced by overexpression of NPM1 and PTPN14 together, but not by overexpression of NPM1 alone. When both NPM1 and PTPN14 were overexpressed, nuclear translocation of YAP was significantly inhibited.

Finally, we found that NPM1 overexpression increased the $\mathrm{IC}_{50}$ of sorafenib in a manner that was partially reversed by knockdown of YAP expression (Fig. 7D). Taken together, these results suggest that NPM1 is responsible, at least in part, for regulation of YAP by retaining PTPN14 in the nucleus under hypoxic conditions (Fig. 8). Furthermore, inhibition of PTPN14 causes HCC to become more chemoresistant to sorafenib under hypoxic conditions [11] (Additional file 1).

\section{Discussion}

The findings of this study elucidated certain aspects of the mechanism by which hypoxia induces chemoresistance to sorafenib in HCC. Our data suggested that the mechanism may be initiated by hypoxic stress, triggering the translocation of NPM1 from the nucleolus into the nucleus. We speculate that once in the nucleus, NPM1 complexes with PTPN14, preventing its interaction with YAP. Increased YAP activity promotes cell proliferation, survival, stemness, migration, invasion and chemoresistance.

PTPN14 is a nonreceptor protein tyrosine phosphatase that is involved in regulating a variety of cellular processes, including cell adhesion, cell growth, differentiation and cancer progression. PTPN14 mutations have been identified in a variety of human malignancies, including breast cancer, colon cancer, and skin basal cell carcinoma [25-27], and thus PTPN14 has been implicated as a putative tumor and metastasis suppressor. Several potential substrates for PTPN14, including $\beta$-catenin [28], p130Cas [29], RIN1 and PRKCD [30], and YAP [14], are all related to tumor progression and metastasis.

Liu et al. [14] demonstrated that YAP was a direct substrate of PTPN14. The authors showed that inhibition of YAP's transcriptional co-activator function by PTPN14 was mediated by direct protein interactions, the result of which was increased levels of cytoplasmic phosphorylated YAP, which is inactive. They further showed that knockdown of PTPN14 induced nuclear retention of YAP and increased YAP-dependent cell migration. Mello et al. [16], studying pancreatic cancer cells, found that PTPN14 suppressed the YAP activity that was necessary for $\mathrm{p} 53$ tumor suppressor function; a p53 transcriptional activation mutant showed elevated tumor suppression capacity because of hyperactivation of PTPN14.

Dai et al. [11] reported that YAP participates in hypoxia-induced chemoresistance. They found that activation of YAP under hypoxic conditions correlated with resistance to the chemotherapeutic agent $\mathrm{SN} 38$, a topoisomerase I inhibitor. This mechanism appeared to be independent of HIF1- $\alpha$ [13]. These findings suggested that YAP was involved in more than one pathway responsible for tumorigenesis, increasing the list of possible anti-tumor targets.

The trigger for all of these hypoxia-related events may involve NPM1. Yang et al. [20] used a model of oxidation-mediated nucleolar stress and found that cellular stresses triggered the glutathionylation of NPM1, causing it to dissociate from nucleic acids and thereby become active. In their model, activated NPM1 was essential for the stress-induced activation of p53. Several lines of evidence suggest that NPM1 activation is a common pathway for responses to several kinds of cellular stress, including exposure to chemotherapeutic agents [31, 32], heat shock [33, 34] and UV radiation [35-37]. Li et al. [38] reported that NPM1 is induced by hypoxia and protects human breast cancer cells against 


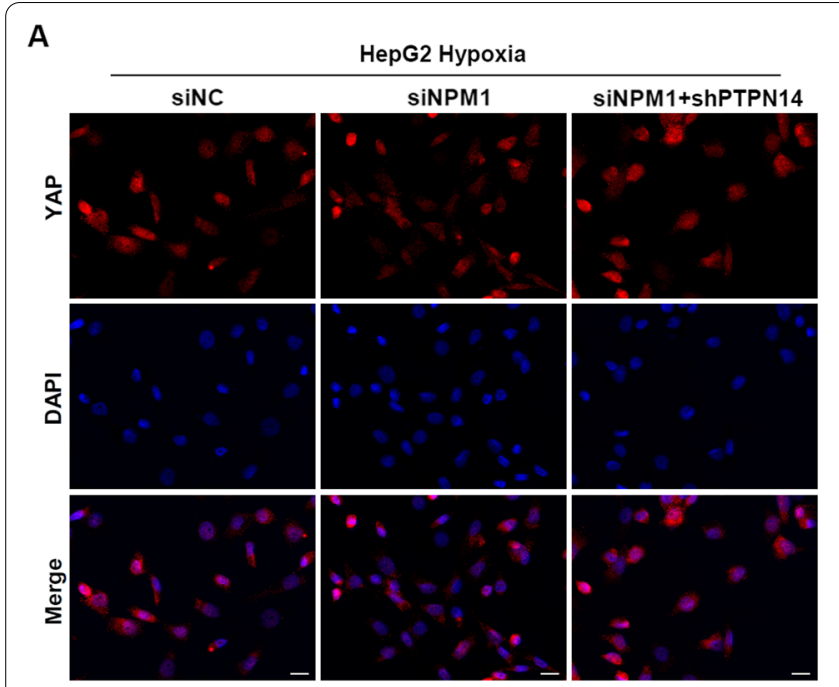

B

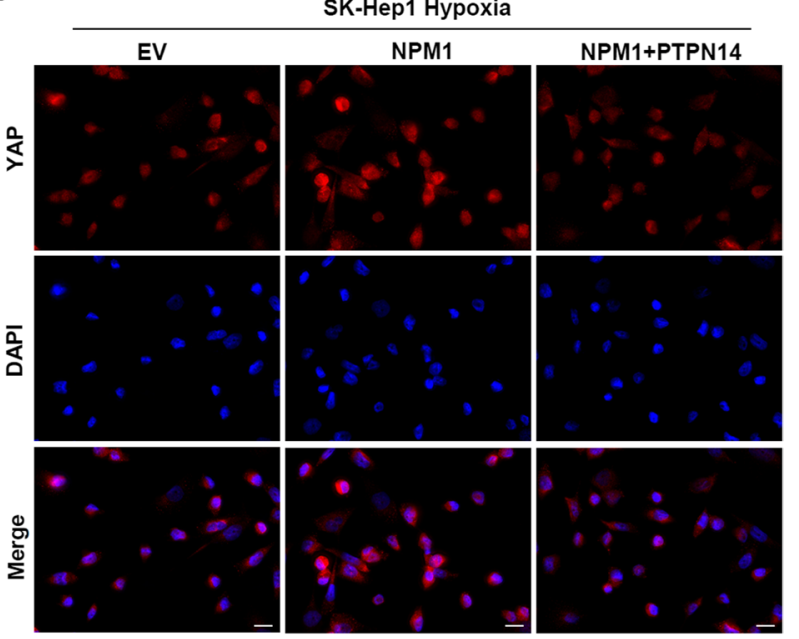

C

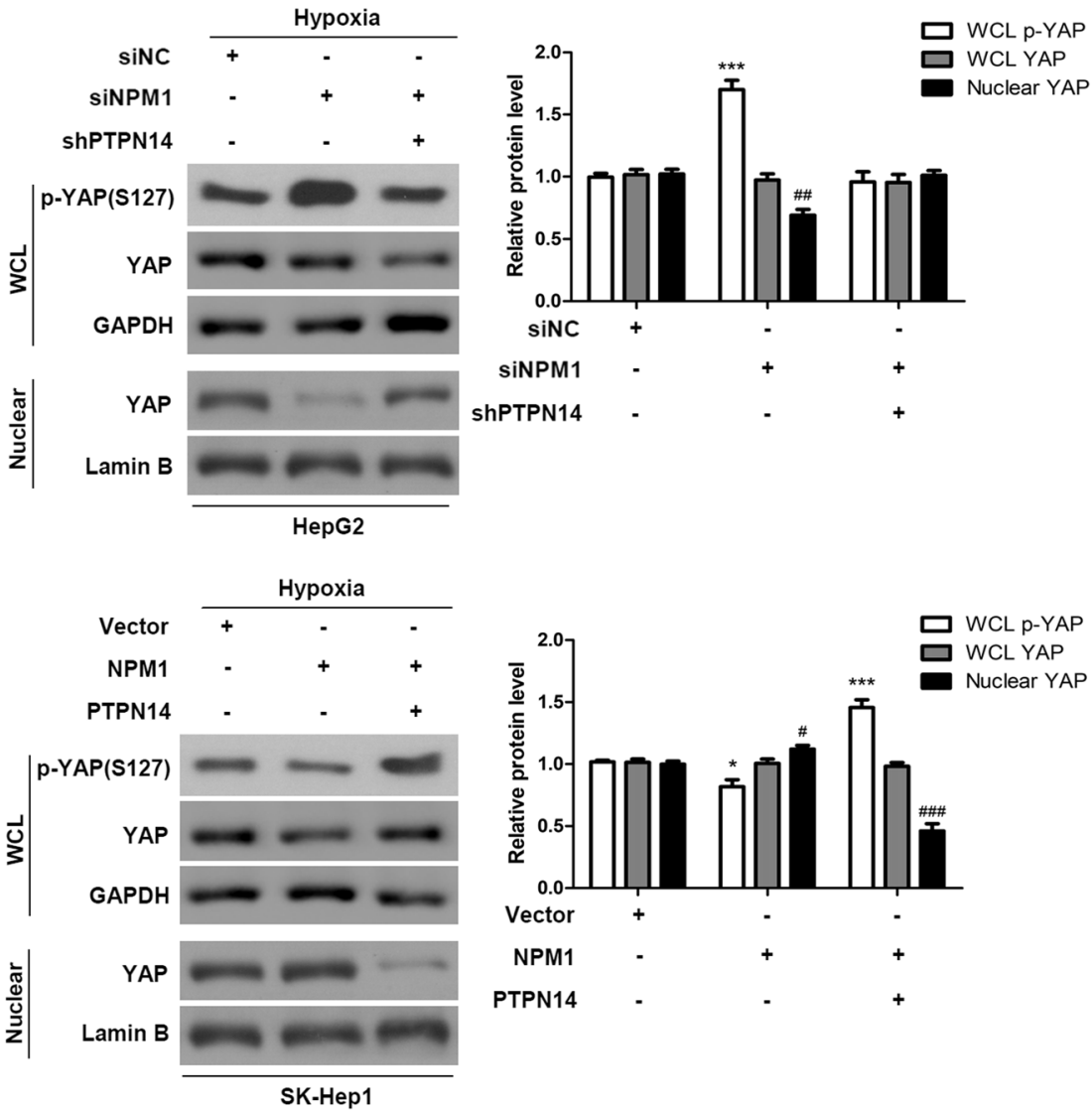

D

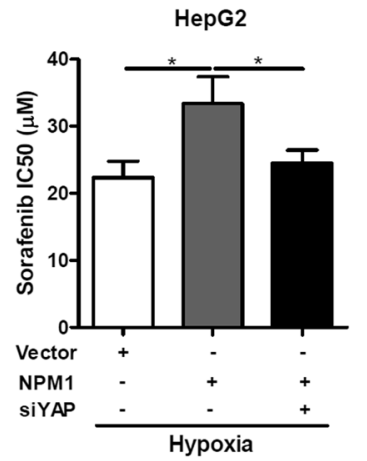

Fig. 7 NPM1 regulates YAP by retaining PTPN14 in the nucleus under hypoxia. Representative immunofluorescence staining of the localization of YAP in HepG2 cells with NPM1 or/and PTPN14 knockdown (A) and SK-Hep1 cells with NPM1 or/and PTPN14 overexpression (B) under hypoxia (2\% $\mathrm{O}_{2}$ ) for $24 \mathrm{~h}$. Scale bar $=20 \mu \mathrm{m}$. C The expression of $\mathrm{p}$-YAP and total YAP in the whole cell lysate (WCL) and nuclear fractions of HepG2 cells with NPM1 or/and PTPN14 knockdown and SK-Hep1 cells with NPM1 or/and PTPN14 overexpression under hypoxia (2\% $\left.\mathrm{O}_{2}\right)$ for $24 \mathrm{~h}$ was examined by western blotting. $\mathbf{D}$ The $\mathrm{IC}_{50}$ was measured using an MTT assay after $72 \mathrm{~h}$ of sorafenib treatment. ${ }^{*} p<0.05$ 


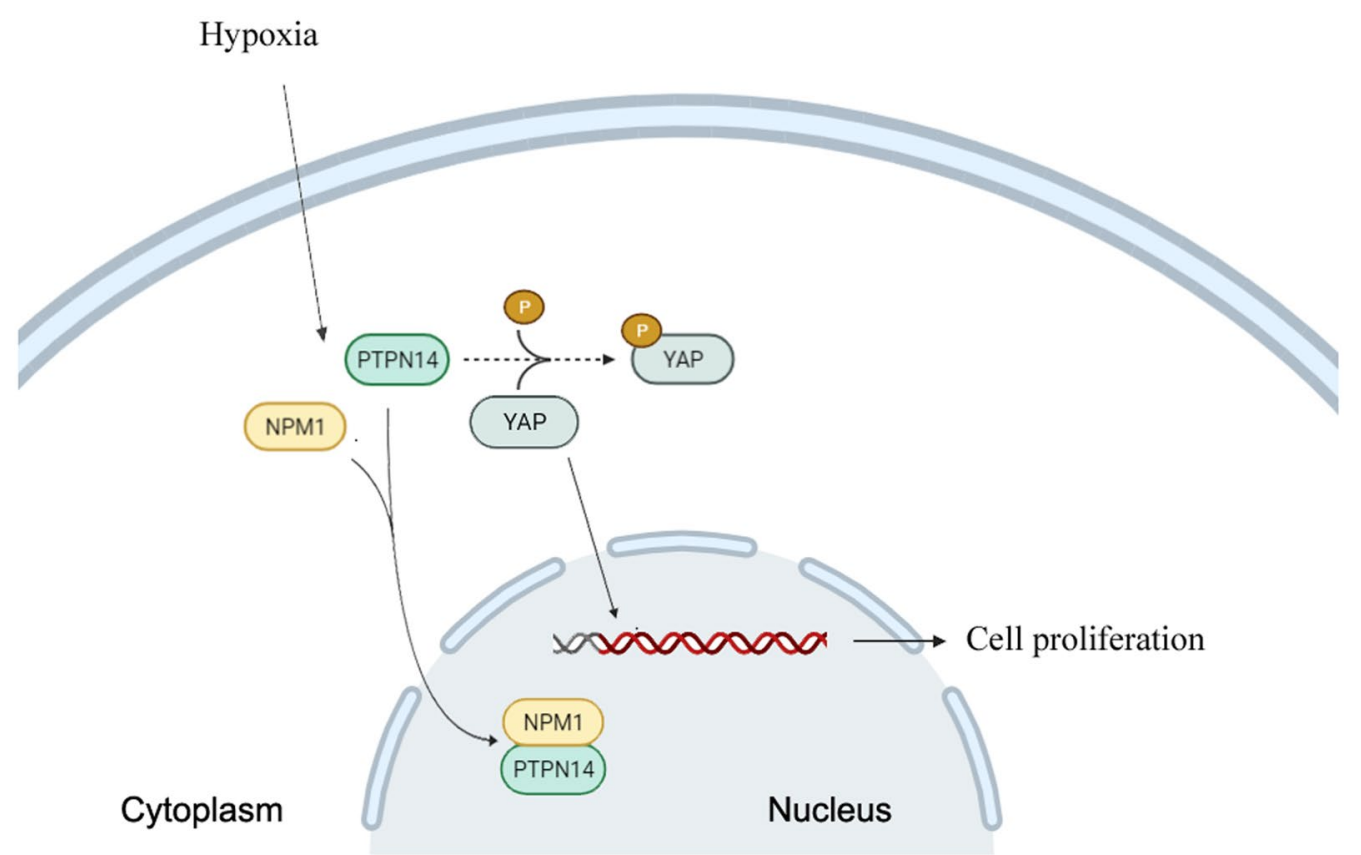

Fig. 8 Schematic diagram of hypoxia-induced NPM1 combined with PTPN14 attenuating inhibition of YAP

hypoxic cell death. Consistent with previous studies, the present study demonstrated that hypoxia triggered the release of NPM1 from nucleoli, suggesting that NPM1 expression is hypoxia responsive.

In HCC, Liu et al. [14] found that NPM1 was highly expressed and facilitated cell proliferation, whereas ATF5 inhibited proliferation. Their findings demonstrated a mechanistic link between elevated NPM1 expression and depressed ATF5 in HCC, suggesting that regulation of ATF5 by NPM1 participates in cell proliferation in HCC.

The mechanisms by which NPM1 modulates the effects of cell cycle pathways have been the subject of several studies, including that of Di Matteo et al. [39], who studied the interaction of NPM1 with the tumor suppressor Fbw7 $\gamma$. They found that NPM1 bound to a nucleolar localization signal (NoLS) in Fbw7 $\gamma$. The authors suggested that the NoLS interaction may serve as a potential target in cancer therapeutics.

The mechanism suggested in our present study involves a variation on the tumor-suppressive mechanisms mentioned in these previous studies. In our model, NPM1 binds to PTPN14 under hypoxic conditions, retaining PTPN14 in the nucleus and preventing its interaction with YAP, that under normal conditions results in YAP maintaining its inactive (phosphorylated) state. As a result, HCC continues to proliferate and metastasize, resulting in larger hypoxic tumor volumes and continuing the cycle of hypoxic stress.

\section{Conclusions}

Our mechanistic study suggested that NPM1 mediates PTPN14 localization, and regulates YAP by retaining PTPN14 in the nucleus under hypoxic conditions in HCC. Taken together, our data suggest that a therapeutic strategy against hypoxia-induced sorafenib-resistance to HCC may involve disruption of the NPM1/PTPN14/YAP axis.

\section{Abbreviations}

HCC: Hepatocellular carcinoma; YAP: Yes-associated protein; HIF-1a: Hypoxiainducible factor-1a; PTPN14: Protein tyrosine phosphatase non-receptor type 14; NLS: Nuclear localization sequence; NPM1/B23: Nucleophosmin; ATF5: Activating transcription factor 5; TMA: Tissue microarrays; FBS: Fetal bovine serum; H-score: Histochemistry score; qRT-PCR: Quantitative real-time polymerase chain reaction; Co-IP: Co-immunoprecipitation.

\section{Supplementary Information}

The online version contains supplementary material available at https://doi. org/10.1186/s12935-022-02479-0.

Additional file 1: Figure S1. HE detection of lung metastasis sections.

\section{Acknowledgements}

Not applicable.

\section{Authors' contributions}

DZ, FW and JS performed experiments, collected and analyzed the data and drafted the manuscript. MM, XF, CL, QW, SF and LZ performed experiments and collected the data. BT, YY, JT and MX assisted in analyzing the data. ZZ and JJ conceived and designed the study, performed data analysis and interpretation. All authors read and approved the final manuscript. 


\section{Funding}

This study was supported by the National Key Research and Development projects intergovernmental cooperation in science and technology of China (2018YFE0126900), National Natural Science Foundation of China (81803778, 81901848), Natural Science Foundation of Zhejiang Province (LY20H180016, LQ20H160055), and The Medical and Health Care Project of Zhejiang Province (2018KY933, 2020KY380)

\section{Availability of data and materials}

The datasets used and/or analyzed during the current study are available from the corresponding author upon reasonable request.

\section{Declarations}

\section{Ethics approval and consent to participate}

The Ethics Committee of Lishui Hospital of Zhejiang University approved this study. The protocols were carried out in accordance with the Declaration of Helsinki. Informed consent was obtained from all patients. Animal studies were approved by the Lishui Hospital of Zhejiang University, Zhejiang, China.

\section{Consent for publication}

Not applicable.

\section{Competing interests}

The authors declare that they have no competing interests.

Received: 27 July 2021 Accepted: 20 January 2022

Published online: 08 February 2022

\section{References}

1. Torre LA, Bray F, Siegel RL, Ferlay J, Lortet-Tieulent J, Jemal A. Global cancer statistics, 2012. CA Cancer J Clin. 2015;65(2):87-108.

2. Ferlay J, Steliarova-Foucher E, Lortet-Tieulent J, Rosso S, Coebergh JW, Comber H, Forman D, Bray F. Cancer incidence and mortality patterns in Europe: estimates for 40 countries in 2012. Eur J Cancer. 2013;49(6):1374-403.

3. Maluccio M, Covey A. Recent progress in understanding, diagnosing, and treating hepatocellular carcinoma. CA Cancer J Clin. 2012;62(6):394-9.

4. Hussain K, El-Serag HB. Epidemiology, screening, diagnosis and treatment of hepatocellular carcinoma. Minerva Gastroenterol Dietol. 2009;55(2):123-38.

5. Schutte K, Bornschein J, Malfertheiner P. Hepatocellular carcinoma-epidemiological trends and risk factors. Dig Dis. 2009;27(2):80-92.

6. Fattovich G, Stroffolini T, Zagni I, Donato F. Hepatocellular carcinoma in cirrhosis: incidence and risk factors. Gastroenterology. 2004;127(5 Suppl 1):S35-50.

7. Llovet JM, Bruix J. Molecular targeted therapies in hepatocellular carcinoma. Hepatology. 2008;48(4):1312-27.

8. Zhu J, Yin T, Xu Y, Lu XJ. Therapeutics for advanced hepatocellular carcinoma: recent advances, current dilemma, and future directions. J Cell Physiol. 2019;234(8):12122-32.

9. Chang HY, Chang TC, Huang WY, Lee CT, Yen CJ, Tsai YS, Tzai TS, Chen SH, Chow NH. RON nuclear translocation under hypoxia potentiates chemoresistance to DNA double-strand break-inducing anticancer drugs. Mol Cancer Ther. 2016;15(2):276-86.

10. Doktorova H, Hrabeta J, Khalil MA, Eckschlager T. Hypoxia-induced chemoresistance in cancer cells: the role of not only HIF-1. Biomed Pap Med Fac Univ Palacky Olomouc Czech Repub. 2015;159(2):166-77.

11. Dai $X Y$, Zhuang LH, Wang DD, Zhou TY, Chang LL, Gai RH, Zhu DF, Yang $\mathrm{B}, \mathrm{Zhu} \mathrm{H}, \mathrm{He}$ QJ. Nuclear translocation and activation of YAP by hypoxia contributes to the chemoresistance of SN38 in hepatocellular carcinoma cells. Oncotarget. 2016;7(6):6933-47.

12. Valero V 3rd, Pawlik TM, Anders RA. Emerging role of Hpo signaling and YAP in hepatocellular carcinoma. J Hepatocell Carcinoma. 2015;2:69-78.

13. Zhang X, Li Y, Ma Y, Yang L, Wang T, Meng X, Zong Z, Sun X, Hua X, $\mathrm{Li} \mathrm{H}$. Yes-associated protein (YAP) binds to HIF-1alpha and sustains HIF-1alpha protein stability to promote hepatocellular carcinoma cell glycolysis under hypoxic stress. J Exp Clin Cancer Res. 2018;37(1):216.
14. Liu X, Yang N, Figel SA, Wilson KE, Morrison CD, Gelman IH, Zhang J. PTPN14 interacts with and negatively regulates the oncogenic function of YAP. Oncogene. 2013;32(10):1266-73.

15. Wilson KE, Li YW, Yang N, Shen H, Orillion AR, Zhang J. PTPN14 forms a complex with Kibra and LATS1 proteins and negatively regulates the YAP oncogenic function. J Biol Chem. 2014;289(34):23693-700.

16. Mello SS, Valente LJ, Raj N, Seoane JA, Flowers BM, McClendon J, Bieging-Rolett KT, Lee J, Ivanochko D, Kozak MM, et al. A p53 supertumor suppressor reveals a tumor suppressive p53-Ptpn14-Yap axis in pancreatic cancer. Cancer Cell. 2017;32(4):460-473 e466.

17. Michaloglou C, Lehmann W, Martin T, Delaunay C, Hueber A, Barys L, Niu H, Billy E, Wartmann M, Ito M, et al. The tyrosine phosphatase PTPN14 is a negative regulator of YAP activity. PLOS ONE. 2013;8(4):e61916.

18. Liang G, Duan C, He J, Ma W, Dai X. PTPN14, a target gene of miR-4295, restricts the growth and invasion of osteosarcoma cells through inactivation of YAP1 signalling. Clin Exp Pharmacol Physiol. 2020:47(7):1301-10.

19. Wadham C, Gamble JR, Vadas MA, Khew-Goodall Y. Translocation of protein tyrosine phosphatase Pez/PTPD2/PTP36 to the nucleus is associated with induction of cell proliferation. J Cell Sci. 2000;113(Pt 17):3117-23.

20. Yang $K$, Wang M, Zhao Y, Sun X, Yang Y, Li X, Zhou A, Chu H, Zhou H, Xu J, et al. A redox mechanism underlying nucleolar stress sensing by nucleophosmin. Nat Commun. 2016;7:13599.

21. Fukawa T, Ono M, Matsuo T, Uehara H, Miki T, Nakamura Y, Kanayama $\mathrm{HO}$, Katagiri T. DDX31 regulates the p53-HDM2 pathway and rRNA gene transcription through its interaction with NPM1 in renal cell carcinomas. Can Res. 2012;72(22):5867-77.

22. Liu X, Liu D, Qian D, Dai J, An Y, Jiang S, Stanley B, Yang J, Wang B, Liu DX. Nucleophosmin (NPM1/B23) interacts with activating transcription factor 5 (ATF5) protein and promotes proteasome- and caspase-dependent ATF5 degradation in hepatocellular carcinoma cells. J Biol Chem. 2012;287(23):19599-609.

23. Gho JW, Ip WK, Chan KY, Law PT, Lai PB, Wong N. Re-expression of transcription factor ATF5 in hepatocellular carcinoma induces G2-M arrest. Cancer Res. 2008;68(16):6743-51.

24. Azim HA Jr, Peccatori FA, Brohee S, Branstetter D, Loi S, Viale G, Piccart M, Dougall WC, Pruneri G, Sotiriou C. RANK-ligand (RANKL) expression in young breast cancer patients and during pregnancy. Breast Cancer Res. 2015;17:24.

25. Sjoblom T, Jones S, Wood LD, Parsons DW, Lin J, Barber TD, Mandelker D, Leary RJ, Ptak J, Silliman N, et al. The consensus coding sequences of human breast and colorectal cancers. Science. 2006;314(5797):268-74.

26. Wang Z, Shen D, Parsons DW, Bardelli A, Sager J, Szabo S, Ptak J, Silliman $\mathrm{N}$, Peters BA, van der Heijden MS, et al. Mutational analysis of the tyrosine phosphatome in colorectal cancers. Science. 2004;304(5674):1164-6.

27. Bonilla X, Parmentier L, King B, Bezrukov F, Kaya G, Zoete V, Seplyarskiy VB, Sharpe HJ, McKee T, Letourneau A, et al. Genomic analysis identifies new drivers and progression pathways in skin basal cell carcinoma. Nat Genet. 2016;48(4):398-406

28. Wadham C, Gamble JR, Vadas MA, Khew-Goodall Y. The protein tyrosine phosphatase Pez is a major phosphatase of adherens junctions and dephosphorylates beta-catenin. Mol Biol Cell. 2003;14(6):2520-9.

29. Zhang P, Guo A, Possemato A, Wang C, Beard L, Carlin C, Markowitz SD, Polakiewicz RD, Wang Z. Identification and functional characterization of p130Cas as a substrate of protein tyrosine phosphatase nonreceptor 14. Oncogene. 2013;32(16):2087-95.

30. Belle L, Ali N, Lonic A, Li X, Paltridge JL, Roslan S, Herrmann D, Conway JR, Gehling FK, Bert AG, et al. The tyrosine phosphatase PTPN14 (Pez) inhibits metastasis by altering protein trafficking. Sci Signal. 2015;8(364):ra18.

31. Chan PK, Bloom DA, Hoang TT. The N-terminal half of NPM dissociates from nucleoli of HeLa cells after anticancer drug treatments. Biochem Biophys Res Commun. 1999;264(1):305-9.

32. Chan PK. Characterization and cellular localization of nucleophosmin/ B23 in HeLa cells treated with selected cytotoxic agents (studies of B23-translocation mechanism). Exp Cell Res. 1992;203(1):174-81.

33. Kodiha M, Banski P, Stochaj U. Computer-based fluorescence quantification: a novel approach to study nucleolar biology. BMC Cell Biol. $2011 ; 12: 25$. 
34. Su H, Kodiha M, Lee S, Stochaj U. Identification of novel markers that demarcate the nucleolus during severe stress and chemotherapeutic treatment. PLoS ONE. 2013;8(11):e80237.

35. Kurki S, Peltonen K, Latonen L, Kiviharju TM, Ojala PM, Meek D, Laiho M. Nucleolar protein NPM interacts with HDM2 and protects tumor suppressor protein $\mathrm{p} 53$ from HDM2-mediated degradation. Cancer Cell. 2004:5(5):465-75.

36. Box JK, Paquet N, Adams MN, Boucher D, Bolderson E, O'Byrne KJ, Richard DJ. Nucleophosmin: from structure and function to disease development BMC Mol Biol. 2016;17(1):19.

37. Colombo E, Marine JC, Danovi D, Falini B, Pelicci PG. Nucleophosmin regulates the stability and transcriptional activity of p53. Nat Cell Biol. 2002:4(7):529-33.

38. Li J, Zhang X, Sejas DP, Bagby GC, Pang Q. Hypoxia-induced nucleophosmin protects cell death through inhibition of p53. J Biol Chem. 2004;279(40):41275-9.

39. Di Matteo A, Franceschini M, Paiardini A, Grottesi A, Chiarella S, Rocchio S, Di Natale C, Marasco D, Vitagliano L, Travaglini-Allocatelli C, et al. Structural investigation of nucleophosmin interaction with the tumor suppressor Fbw7gamma. Oncogenesis. 2017;6(9):e379.

\section{Publisher's Note}

Springer Nature remains neutral with regard to jurisdictional claims in published maps and institutional affiliations.

- fast, convenient online submission

- thorough peer review by experienced researchers in your field

- rapid publication on acceptance

- support for research data, including large and complex data types

- gold Open Access which fosters wider collaboration and increased citations

- maximum visibility for your research: over $100 \mathrm{M}$ website views per year

At BMC, research is always in progress.

Learn more biomedcentral.com/submissions 